Periodontal hastalığa sahip bireylerde periodontal tedavinin tat duyusu üzerine etkisi

\section{The effect of periodontal treatment on taste perception in periodontally involved patients}

\section{Dr. Dt. Fatma Karacaoğlu}

Ankara Üniversitesi Diş Hekimliği Fakültesi Periodontoloji A. D., Ankara.

\section{Dr. Dt. Seyda Alkan}

Bayındır Sağlık Grubu, İş Kule Diş Kliniği, İstanbul.

\section{Prof. Dr. Murat Akkaya}

Ankara Üniversitesi Diş Hekimliği Fakültesi

Periodontoloji A. D., Ankara.

Geliş tarihi: 2 Kasım 2017

Kabul tarihi: 21 Mart 2018

doi: $10.5505 /$ yeditepe.2018.42243

\section{Yazışma adresi:}

Dr. Dt. Fatma Karacaoğlu

Ankara Üniversitesi Diş Hekimliği Fakültesi

Periodontoloji A.D. 06500 Çankaya, Ankara.

Telefon: (0312)2965685

Faks No: (0312)2123954

E-posta: fboke@ankara.edu.tr

\section{ÖZET}

Amaç: Bu çalışmanın amacı gingivitis ve periodontitis teşhisi konulmuş hastalarda cerrahi olmayan periodontal tedaviyi takiben tat duyusu değişiklikleri ve klinik parametreler arasındaki ilişkiyi ortaya koymaktır.

Gereç ve Yöntem: Yaş ortalamaları 37,5 olan 17 kadın, 23 erkek toplam 30 gingivitis; yaş ortalamaları 39,6 olan 13 kadın, 17 erkek toplam 30 generalize kronik periodontitis hastası değerlendirilmiştir. Hastaların yaşları, cinsiyetleri, sistemik durumları, oral hijyen alışkanlıkları ve bunların sıklığı ve tat duyusu şikayetlerini içeren bir form doldurulmuştur. Tat duyusu 9 ayrı solüsyonla ölçülmüştür. Hastaların periodontal durumunu klinik olarak değerlendirmek için her dişin 6 yüzeyinden plak indeks (Pi) ve gingival indeks (Gi) değerleri, klinik ataçman kaybı (KAK), cep derinliği(CD), sondalamada kanama indeksi(SKi) değerleri kaydedilmiştir.

Bulgular: Her iki gruptaki hastalardan elde edilen $\mathrm{PI}, \mathrm{Gl}, \mathrm{CD}$ ve SKi skorları ortalamalarında başlangıç değerlere kıyasla istatistiksel olarak anlamlı düzeyde azalma görülmüştür. KAK skorları karşılaştırıldığında ise periodontitis grubunda istatistiksel olarak anlamlı bir azalma varken, gingivitis grubunda anlamlı bir değişiklik olmamıştır. Gingivitis grubunda tuzlu tat ile ilgili değerlerde istatistiksel olarak anlamlı bir değişiklik olmazken diğer bütün tatlarda (tatlı, ekşi, acı) bu değişim pozitif yönde istatistiksel olarak anlamlıdır. Periodontitis grubunda ise bütün tatlardaki değişim pozitif yönde ve istatistiksel olarak anlamlıdır.

Sonuçlar: Bu çalışmanın sonuçları periodontal hastalığa sahip bireylerde görülen tat duyusu bozukluğunun periodontal tedavi ile azaltılabileceğini göstermiştir.

Anahtar kelimeler: Gingivitis, periodontitis, tat duyusu bozukluğu.

\section{SUMMARY}

Introduction: The purpose of this study is to evaluate the relation between clinical parameters and alterations in taste perception after non-surgical periodontal treatment in patients diagnosed with gingivitis and periodontitis.

Materials and Methods: A total of 30 patients, 17 female and 23 male, with a mean age of 35.7 with gingivitis and 30 patients 13 female and 17 male, with a mean age of 39.6, with Periodontitis were evaluated. Patients filled in the forms which content information about age, cender, oral hygiene habit and its frequency, systemic diseases and complaints of taste disorder. Taste perception was measured with 9 different solutions. Due to clinical periodontal evaluation of teeth the Plaque index (PI) and Gingival index (GI) values obtained from 6 surface of teeth, clinical atachment loss (CAL), probing depth $(\mathrm{PD})$, and Bleeding on probing (BOP) values were established.

Results: There become a statistically significant decrease in average scores of PI, GI, PD, and BOP that were obtained from 
both groups of patients, in comparison with the initial scores. There was not a statistically significant decrease in gingivitis, but in periodontitis group as CAL scores were compared. In gingivitis group, there was not a significant difference in salty taste, but in other tastes (bitter, sour, sweet). This difference is positive. In periodontitis group, difference of all tastes is positive and statistically significant.

Conclusion: Results of this study show that taste disorders associated with periodontal disease can be reduced by periodontal therapy.

Keywords: Gingivitis, periodontitis, taste disorders

\section{Giriş}

Tat, ağız içerisinde eriyik haldeki uyarıcıları fark etme ve tanıma anlamına gelmektedir. Tat sistemi 5 temel uyaranı ayırt eder: Acı, tuzlu, ekşi, tatlı ve umami. ${ }^{1}$ Ağzımıza aldığımız bir yiyeceğin tadının algılanabilmesi için, o maddenin tat tomurcuklarına kadar ulaşması ve kimyasal yapısıyla tat tomurcuklarında sonlanan özel tat liflerinin uyarılması ile bir uyaranın merkeze kadar iletilmesi gerekmektedir. ${ }^{2}$ Tat bozuklukları genelde sanıldığından daha sıktır. Tat bozukluklarının başlıca nedenleri arasında kranioserebral hasar, üst solunum yolu enfeksiyonu, toksik maddelere maruz kalma, iyatrojenik nedenler (radyasyon, orta kulak cerrahisi, tonsillektomi vs), ilaçların yan etkileri, burning mouth sendromu yer alır. ${ }^{3}$ Tat fonksiyonunu; $n$. fasialis, $\mathrm{n}$. glossofaringeus ve $\mathrm{n}$. vagus travması, diğer oral veya maksillofasial travmalar, dental veya alveolar cerrahi (diş çekimi, periodontal cerrahi, biopsi), pürülent cerahat üreten intraoral enfeksiyonlar ve kötü oral hijyen etkileyebilir. Kötü oral hijyen özellikle protez ya da geniş restorasyonlu dişlerde, kronik istenmeyen tat değişikliğiyle sonuçlanabilir. Gingivitis ve bakteriyel, fungal enfeksiyonlar tat bozukluğu nedenlerinin başını çekebilir. ${ }^{4}$ Sistemik ilaç kullanımı da gıdanın koku ve dokunma özelliklerinde değişikliğe, ağız kuruluğuna (tükürük akışı kaybına bağlı olarak) ve ağızda yanıcı ağrıya dolayısıyla tat bozukluğuna yol açabilir. ${ }^{3,5}$ Tat değişiklikleri sadece hissizlik, tat duyusunda hassasiyetin azalması ya da tat duyusunda total kayıp olarak gözlenebilir. ${ }^{6}$

Yetişkin popülasyonda oldukça sık görülen periodontal ve gingival hastalıklar, plağa bağlı dişetinde enflamasyon olarak başlayıp, alveol kemik rezorpsiyonu ile birlikte diş destek doku kaybına yol açan kronik enflamatuar hastalıklardır. Gingivitis ve periodontitisi de içeren birçok oral enflamasyon tat duyusunu etkileyebilmektedir. ${ }^{4}$

Oral hijyen, gingival ve periodontal hastalığın tat duyusunda değişiklik yaptığı düşünülmesine rağmen bu konuda yayınlanmış ayrıntılı bir literatür mevcut değildir. Araştırmamızın amacı Türk toplumunu yaklaşık \%90'ını ${ }^{7}$ etkileyen periodontal hastalıkların tat duyusunda herhangi bir değişikliğe neden olup olmadığını değerlendirmek için tat duyusunu etkileyecek herhangi bir hastalığı olmayan ve ilaç kullanmayan gingivitis ve kronik periodontitisli hastalarda tedavi öncesi ve tedavi sonrası dönemlerde klinik parametrelerle incelemektir.

\section{GEREÇ VE YÖNTEM}

\section{Hasta ve kontrol grubunun belirlenmesi}

Çalışma Ankara Üniversitesi Diş Hekimliği Fakültesi Etik Kurulu tarafından onaylanmıştır (Tarih: 12/10/2004; Sayı: 77). Çalışma grubu Nisan 2005- Ocak 2006 tarihleri arasında A.Ü. Diş Hekimliği Fakültesi Periodontoloji Kliniği'ne başvuran hastalar arasından, cinsiyet ve yaş ortalaması iki grup arasında belirgin fark yaratmayacak şekilde, rastgele seçilmiştir. Çalışmaya 30 gingivitis ve 30 generalize kronik periodontitis hastası olmak üzere toplam 60 hasta dahil edilmiştir. Örneklem büyüklüğü için güven aralığı \%95, güç düzeyi \%80 ve tat farkındalığında anlamlıık 4 olarak kabul edildiğinde her grup için gerekli örnek sayısı 26 olarak bulunmuştur. Ancak olabilecek hasta kayıplarını tolere etmek için bu sayı 30'a çıkarılmıştır.

Sistemik hastalığa sahip olan bireyler, sigara kullananlar, tat duyusunu etkileyecek ilaç kullananlar (captopril, fluoksetinhidroklorür, sulfadoksin), tükürük bezi hastalığı olanlar, ağız kuruluğuna sebep olabilecek patolojilere sahip olanlar, ağız solunumu yapanlar, menopoza girmiş veya menstrual siklus içinde olan kadın hastalar, çürük dişi veya ağzında hatalı restorasyon olanlar, sabit ya da hareketli protez kullanan hastalar çalışma dışı bırakılmıştır. Belirtilen kriterlere uyan 60 birey araştırmaya dahil olmadan önce mevcut periodontal hastalıkları, bu hastalıkların tedavisi ve çalışmanın içeriği hakkında bilgilendirilmiş ve yazııı onamları alınarak araştırmaya dahil edilmiştir.

\section{Klinik İnceleme Parametreleri}

Çalışmaya dahil edilen gingivitisli hastaların tüm dişlerinin (üçüncü molarlar hariç) 6 bölgesinden (mesiobukkal, midbukkal, distobukkal, mesiopalatinal, midpalatinal ve distopalatinal); Plak İndeksi (Pi)8, Gingival İndeks (Gi)9, Sondlamada Kanama Indeksi (SKI)10 ve periodontitisli hastaların yine tüm dişlerinin 6 bölgesinden; Plak İndeksi (Pi), Gingival İndeks (Gi), Sondlamada Kanama İndeksi (SKI), Cep Derinliği (CD) ve Klinik Ataçman Seviyesi (KAS) ölçümleri yapılmış ve radyografik görüntüleri değerlendirilmiştir. Çalışmaya katılan tüm hastaların klinik muayenesi tecrübeli ve kalibre olmuş tek bir hekim tarafından ilk randevuda ve tedavileri tamamlandıktan 6 hafta sonra yapılmıştır. Hekimin kalibrasyonu çalışma başlamadan önce yapılmıştı;; 5 gönüllü hasta aynı gün içinde 1 saat aralıkla 2 kez muayene edilmiştir. Tekrarlanabilirlik, skorların birebir aynı veya $1 \mathrm{~mm}$ yakınlıkla tekrarlandığı bölgelerin yüzdesi hesaplanarak belirlenmiştir. İki ölçüm arasında \%85 tutarlılık olması hekimin kalibre olduğunu göstermiştir. 
Klinik muayenede $3 \mathrm{~mm}$ 'den derin cebi olmayan, radyografik kemik kaybı olmayan ve dişetinde klinik enflamasyon bulguları mevcut olan hastalar gingivitis grubunu oluşturmuş, mevcut dişlerin \%30' undan fazlasında $C D \geq 4 \mathrm{~mm}$ ve klinik ataçman kaybı $\geq 2 \mathrm{~mm}$ olan hastalar ise generalize kronik periodontitis grubunu oluşturmuştur.?

\section{Tat Duyusu Tespiti}

\section{Tat Solüsyonlarının Hazırlanması}

Hastaların tat duyusundaki değişiklikleri kaydetmek için 4 ayrı solüsyon hazırlandı. Tatlı, tuzlu, ekşi ve acı tadını içeren solüsyonlar her biri için 9 ayrı konsantrasyonda hazırlandı ve hastalara uygulandı. Solüsyon hazırlanmasında tatlı için sükroz $(0,01 \mathrm{~mol} / \mathrm{L}-1 \mathrm{~mol} / \mathrm{L})$, tuzlu için $\mathrm{NaCl}$ $(0,01 \mathrm{~mol} / \mathrm{L}-1 \mathrm{~mol} / \mathrm{L})$, ekşi için sitrik asit $(0,32 \mathrm{mmol} / \mathrm{L}$ $0,032 \mathrm{mmol} / \mathrm{L})$ ve acı için kinin hidroklorit $(0,01 \mathrm{~mol} / \mathrm{L}-1$ $\mathrm{mol} / \mathrm{L})$ kullanıldı. ${ }^{12}$ Solüsyonlar her hasta için taze hazırlanmıştır. Her bir tat için logaritmik artışla karakterize 9 ayrı derecelendirmede materyal içeren solüsyonlar hazırlandı ve hastaların hangi yoğunluktaki solüsyona cevap verdiği kaydedildi.

Hastaların tat algılarının değerlendirilmesinde hazırlanan solüsyonlar hastalara tedavi öncesi ve tedaviden 6 hafta sonra her bireye tat duyusunda değişikliğe neden olmaması için 5cc'lik cam tüplerde verildi. En seyreltilmiş solüsyon olan 9 numaralı solüsyondan başlanarak solüsyonlar 15 saniye süreyle gargara yaptırıldıktan sonra tat alıp almadıkları soruldu. Her bir solüsyonun arasında ve ilk çalkalatmadan önce hastaların ağızlarını distile suyla çalkalamaları istendi. Tadı tanıdıkları solüsyonun numarası kaydedildi.

Ardından tüm hastalara oral hijyen eğitimi verildi. Gingivitis grubundaki hastalara supra ve subgingival debritman (ultrasonik enstrumantasyon) ve politür işlemi uygulandı. Periodontitis grubundaki hastalara tüm ağız kazıma ve kök yüzey düzleştirmesi işlemleri lokal anestezi altında (ultrasonik aletler ve el aletleri kullanılarak) bir hafta ara ile iki seansta yapıldı. Kök yüzey düzleştirmesi işlemine kök yüzeyi tamamen pürüzsüz hissedilene kadar devam edildi. Daha sonra tüm hastalar, oral hijyen uyumluluğunu ve diş eti enflamasyonunun kontrolünü sağlamak için 6 hafta takip edildi. 6 hafta sonunda parametreler tekrar değerlendirildi.

\section{İstatistiksel Analiz}

Çalışmanın sonucunda elde edilen tüm verilerin analizi bilgisayar ortamında SPSS programı kullanılarak yapıldı. Her grup için yaş ve cinsiyet değerlendirildi. Tedavi öncesi ve sonrası değişiklikler hesaplandıktan sonra verilerin normal dağılıp dağılmadığı Shapiro-wilk testi ile değerlendirildi. Veriler normal dağılım göstermediği için tedavi öncesi ve sonrası elde edilen değerleri gruplar içinde fark olup olmadığı ve farklılıkların anlamlılıkları için Wilcoxon t-tesi ve Ki Kare testi (Chi-Square) uygulandı. Tedavi öncesi ve sonrası dönemlerdeki değişiklikler hesaplandıktan sonra farkın gruplar arasında istatistiksel anlamlılığı Mann Whitney U testi ile incelendi. Tedavi öncesi ve sonrası elde edilen değerlerin yüzde değişim oranları karşılaştırıldı.

\section{BULGULAR}

Çalışmaya yaş ortalaması 35,7 (25-60) olan 30 gingivitis (17 kadın 13 erkek) ve yaş ortalaması 39,6 (30-60) olan 30 generalize kronik periodontitis (13 kadın 17 erkek) hastası olmak üzere toplam 60 hasta dahil edilmiştir. Çalışmaya katılan hastaların yaş ve cinsiyet dağıımı açısından gruplar arasında istatistiksel olarak anlamlı fark bulunmamıştır ( $p>0,05)$ (Tablo 1).

Tablo 1. Demografik veriler

\begin{tabular}{|l|c|c|c|}
\hline & Gingivitis & Kronik Periodontitis & $\boldsymbol{p}$ \\
\hline Yaş & $37.5 \pm 10.7$ & $39.6 \pm 9.8$ & 0.492 \\
\hline Kadın/Erkek & $17 / 13$ & $13 / 17$ & 0.217 \\
\hline
\end{tabular}

Çalışma popülasyonunu oluşturan hastaların tedavi öncesi ve tedavi sonrası klinik parametreleri Tablo 2 ve 3 'de verilmiştir. Her iki grupta da tedavi sonrası klinik parametrelerde tedavi öncesine oranla istatistiksel olarak anlamlı düzelme izlenmiştir $(p<0,05)$.

Tablo 2. Gingivitis grubundaki hastaların tedavi öncesi ve sonrası Pl, Gi, SKi\% değerleri

\begin{tabular}{|l|c|c|c|c|c|c|}
\hline & \multicolumn{2}{|c|}{ PI } & \multicolumn{2}{c|}{ GI } & \multicolumn{2}{c|}{ SKİ (\%) } \\
\hline & TÖ & TS & TÖ & TS & TÖ & TS \\
\hline Ortalama & 1.6 & 0.3 & 0.9 & 0.07 & 45 & 4.5 \\
$($ min-max) & $(0.3-3)$ & $(0.01-0.9)$ & $(0.1-2)$ & $(0.00-0.5)$ & $(8-100)$ & $(0-13)$ \\
\hline$p$ & \multicolumn{2}{|c|}{$-\mathbf{4 . 7 8 5 *}^{*}$} & \multicolumn{2}{|c|}{$-\mathbf{4 . 5 4 3 *}^{*}$} & $-\mathbf{- 4 . 7 8 2}^{*}$ \\
\hline
\end{tabular}

*Tedavi öncesi ve sonrası arası değișim istatistiksel olarak anlamlı $(p<0,05)$ PI: Plak indeks; Gi: Gingival indeks; SKi: Sondalamada kanama indeksi

Tablo 3. Periodontitis grubundaki hastaların tedavi öncesi ve sonrası PI, Gi, CD KAS, SKi\% değerleri

\begin{tabular}{|c|c|c|c|c|c|c|c|c|c|c|}
\hline & \multicolumn{2}{|c|}{ Pİ } & \multicolumn{2}{|c|}{ Gi } & \multicolumn{2}{|c|}{$\mathrm{CD}(\mathrm{mm})$} & \multicolumn{2}{|c|}{ KAS (mm) } & \multicolumn{2}{|c|}{ SK İ(\%) } \\
\hline & Tö & TS & Tö & TS & Tö & TS & Tö & TS & Tö & TS \\
\hline \begin{tabular}{|l|} 
Periodontitis \\
\end{tabular} & & & & & & & & & & \\
\hline Ortalama & 2.1 & 0.2 & 1.3 & 0.08 & 3.2 & 2.4 & 3.1 & 2.6 & 71.4 & 8.2 \\
\hline$($ min-max) & $(1-3)$ & $(0-0.5)$ & $(0.4-2)$ & $(0.0-0.4)$ & $(2.3-4.5)$ & $(1.2-3.8)$ & $(1.24 .8)$ & $(1.2-4.7)$ & $(17-100)$ & $(0-30)$ \\
\hline$p>0.05$ & & $786^{*}$ & & $786^{*}$ & & & & & & \\
\hline
\end{tabular}

*Tedavi öncesi ve sonrası arası değişim istatistiksel olarak anlamlı $(p<0,05) \mathrm{PI}$ Plak indeks; Gi: Gingival indeks; CD: Cep derinliği; KAS: Klinik ataçman seviyesi; SKI: Sondalamada kanama indeksi

Çalışmaya dahil edilen hastaların tedavi öncesi ve tedavi sonrası tat solüsyonlarına vermiş olduğu cevapların değerlendirilmesi Tablo 4'de gösterilmiştir. Çalışmaya dahil edilen hastaların tat solüsyonlarına verdikleri cevapların yüzde değişim değerleri gruplar arası karşılaştırıldığında tatlı, ekşi, acı solüsyonları arasında anlamlı fark bulunmazken tuzlu solüsyonuna cevap açısından anlamlı fark mevcuttur. 
Tablo 4. Hastaların tedavi öncesi ve tedavi sonrası tat solüsyonlarına verdiği cevapların değerlendirilmesi

\begin{tabular}{|c|c|c|c|c|c|c|c|c|}
\hline & \multicolumn{2}{|c|}{ TATLI } & \multicolumn{2}{|c|}{ TUZLU } & \multicolumn{2}{|c|}{ EKŞİ } & \multicolumn{2}{|c|}{ ACI } \\
\hline & TÖ & TS & TÖ & TS & TÖ & TS & TÖ & TS \\
\hline Gingivitis & & & & & & & & \\
\hline $\begin{array}{l}\text { Ortalama } \\
(\min -\max )\end{array}$ & $\begin{array}{l}6.93 \\
(4-9)\end{array}$ & $\begin{array}{r}7.33 \\
(5-9)\end{array}$ & $\begin{array}{r}7.06 \\
(4-9)\end{array}$ & $\begin{array}{l}7.33 \\
(4-9)\end{array}$ & $\begin{array}{l}4.43 \\
(2-8)\end{array}$ & $\begin{array}{l}5.33 \\
(1-9)\end{array}$ & $\begin{array}{c}5.8 \\
(4-8)\end{array}$ & $\begin{array}{l}6.4 \\
(2-9)\end{array}$ \\
\hline$p>0.05$ & \multicolumn{2}{|c|}{$-2.683^{*}$} & \multicolumn{2}{|c|}{$\begin{array}{l}-0.968 \\
\end{array}$} & \multicolumn{2}{|c|}{$-3.255^{*}$} & \multicolumn{2}{|c|}{$-2.646^{*}$} \\
\hline $\begin{array}{l}\text { Periodontitis } \\
\text { Ortalama } \\
\text { (min-max) }\end{array}$ & $\begin{array}{c}7,1 \\
(5-9)\end{array}$ & $\begin{array}{c}8 \\
(6-9)\end{array}$ & $\begin{array}{l}6,4 \\
(3-9)\end{array}$ & $\begin{array}{c}7,1 \\
(4-9)\end{array}$ & $\begin{array}{c}4,1 \\
(2-9)\end{array}$ & $\begin{array}{r}5,7 \\
(3-9)\end{array}$ & $\begin{array}{c}6,2 \\
(4-8)\end{array}$ & $\begin{array}{c}7,1 \\
(4-9)\end{array}$ \\
\hline$p>0.05$ & \multicolumn{2}{|c|}{$\frac{1}{-3.552^{*}}$} & \multicolumn{2}{|c|}{$-2.576^{*}$} & \multicolumn{2}{|c|}{$-3.509^{*}$} & \multicolumn{2}{|c|}{$-2.973^{x}$} \\
\hline
\end{tabular}

*Tedavi öncesi ve sonrası arası değișim istatistiksel olarak anlamlı $(p<0.05)$

\section{TARTIŞMA}

Enflamatuar periodontal hastalıklar hem ağız içerisinde hem de sistemik olarak birçok soruna neden olmaktadır. ${ }^{13-16}$ Gingivitis ve periodontitis sonucu meydana gelen değişikliklere bağlı olarak ağız kokusunun oluştuğ ${ }^{17}$ ve tat duyusunda bozukluk olabileceği ${ }^{4}$ iddia edilmektedir. Bu nedenle, henüz net olarak ortaya koyulmamış olan periodontal hastalık ve tat duyusu arasındaki ilişkiyi incelemeyi amaçladık.

Çalışma grubunda homojeniteyi sağlamak amacıyla çaısşmamızın materyalini oluşturan 30 gingivitis ve 30 periodontitisli hastanın kadın/erkek ve yaş dağııımının sonuçları etkilemeyecek düzeyde olmasına dikkat edilmiştir.

Araşııma materyalimizin 25-60 gibi geniş yaş aralığını kapsaması aynı hastaların tedavi öncesi ve sonrası değer farklarının karşılaştııılması nedeniyle bir sorun yaratmamıştır. Yaşlılarda tat duyusunda azalma gözleyen çeşitli çalışmalar mevcuttur. ${ }^{12,18-20}$ Winkler ve ark. ${ }^{19}$, yaşla beraber tuz ve acı tadın azaldığı ama tatlı ve ekşide değişim olmadığını ifade etmişlerdir. Hyde ${ }^{20}$ ise zaman içerisinde özellikle postmenopozal dönemde tat tomurcuklarının yenilenme sayısının azaldığını belirtmektedir. Delilbaşı ve ark. ${ }^{12}$ post menopozal dönemdeki kadınlarda şeker duyusunda bir azalma olduğu, bu yüzden de menopoz sonrası dönemde şeker tüketiminin arttığını bildirmişlerdir. Bununla birlikte çalışma popülasyonumuzda Dünya Sağlık Örgütü tarafından belirlenen yaşlılık sınırı olan 65 yaş üzeri birey yoktur ve menopoza girmiş kadınların çalışmaya dahil edilmemiştir. Dolayısıyla tat duyusu hastaların yaşından ve cinsiyetinden bağımsız olarak değerlendirilebilmiştir.

Bilgimiz dahilinde, periodontal hastalığı olan bireylerde tedavi öncesi ve sonrası tat duyusunu bizim kullandığımız yönteme benzer yöntemle değerlendiren başka çalışma yoktur. Çalışmamızda hastaların araştırma konusunda bilgilendirilmişler ancak, olası etkilenmeyi önlemek amacıyla tat duyusu testleri sırasında hiçbir yönlendirme yapılmamıştır. Tat duyusu testlerinde tadın etkilenmemesi için taze solüsyonlar ve cam tüpler kullanılmıştır. Logaritmik artışla 9 ayrı konsantrasyonda hazırlanan tatlı, tuzlu, ekşi ve acı solüsyonlarının hasta tarafından değerlendirilmesinde subjektif bir yöntem olan bireyin aldığı tadı derecelendirmesi değil, doğru hissettiği tadın solüsyon numarasının kaydı yöntemi tercih edilmiştir. Tat duyusunu daha detaylı saptamak için de dokuz aşamalı derecelendirme yöntemi kullanılmıştır. Bu da bize tedavi öncesi ve sonrası dönemlerde tat duyusundaki değişimleri daha objektif olarak saptama şansını vermiştir.

Çalışmamızda, her iki grupta tüm klinik parametrelerde bir azalma izlenmiş ve farklar istatistiksel olarak anlamlı bulunmuştur. Bu da gerçekleştirilen periodontal tedavinin sağladığı beklenen bir durumdur.

Tedavi öncesi ve tedavi sonrası dönemlerde uygulanan farklı tatlara ait solüsyonlara verilen yanıt her iki grupta da tedavi sonrası dönemde tedavi öncesi döneme göre olumlu yönde bir artış göstermiştir. Gingivitis grubunda tedavi öncesi dönemde ekşi ve acı tatlarının değerleri maksimum 8 olurken; periodontitis grubunda sadece acı tadında 8 skoru alınmıştır. Ortalama değerlere baktığımızda ise tedavi öncesi dönemde en düşük değerler 4,1 ve 6,2 ile ekşi ve acı tatlara aittir. Tedavi sonrası dönemde elde edilen en düşük skor ise ekşi solüsyonuna aittir. Tedavi öncesi ve tedavi sonrası dönemlerde elde edilen tat skorlarının farklarının grup içi karşılaştırması sonucunda sadece gingivitis grubunda tuzlu tadı hariç diğer tüm tat duyusu testleri arasında istatistiksel olarak anlamlı ve iyileşme yönünde olumlu bir fark bulunmuştur. Gingivitis grubunda her iki dönem arasında tuzlu tadının algılanmasında yine olumlu yönde bir fark izlenirken bu fark istatistiksel olarak anlamlı bulunmamıştır. Gruplar arası karşılaştırmalarda kullandığımız yüzde değişim değerleri karşılaştırıldığında her iki grup arasında sadece tuzlu solüsyona verilen cevapta anlamlı fark gözlenmiştir. Çalışmamızda periodontitis şiddeti ile farklı konsantrasyondaki tatlara verilen yanıtlar arasındaki ilişkinin değerlendirilmemiş olması ise çalışmamızsın bir sınırlılığı olabilir.

Periodontal hastalık nedeniyle oluşan kanama, eksuda ve oluk sıvısı baziktir ve tuzlu bir tadı vardır. Ortamda tuzlu bir tadın mevcut olması dışarıdan alınan tuzlu tadın algılanmasını zorlaştıracağından tuzlu tadın algılanması da enflamasyon varlığında zorlaşabilir. Sonuçlarımıza göre gingivitis grubunda tuzlu tatta araştırma başlangıcı ve tedavi sonrası dönemlerin karşılaştııımasında farkın anlamlı olmaması gingivitis grubunda başlangıçta enflamasyonun periodontitis grubuna göre daha düşük düzeyde olması, başlangıç ve tedavi sonrası dönemlerdeki farkın daha az olmasından kaynaklanıyor olabilir.

Tat duyusundaki düzelme hijyenin düzelmesi sonucu koku ve kötü tada neden olabilecek birikintilerin azalmasına bağlı olabilir; ya da hijyen düzelmesine bağlı periodontal dokulardaki enflamasyonun azalması sonucudur. 
Langan ve Yearick ${ }^{21}$, yaşlılarda yaptıkları çalışmada oral hijyenin düzeltilmesiyle tatlı ve tuzlu tadın algılanmasında anlamlı bir şekilde artış gözlemişlerdir. Ancak bu çalışma tat duyusu ile ağız hijyeni arasında bir ilişki gösterirken tat duyusu ile periodontal hastalık arasında herhangi bir ilişki göstermemiştir. Tat duyusunun oral hijyen alışkanlığının yanı sıra, tükürük akış hızı, reseptör bölgelerindeki farklılıklar gibi bireysel farklılıklardan etkilenebileceği de önceki çalışmalarda bildirilmiştir. ${ }^{22,23}$ Çalışmamızda hastaların oral hijyen alışkanlıklarından etkilenebilecek dil kaplamasının ve hastaların tükürük akış hızlarının değerlendirilmemiş olması ise çalışmamızın sınırlıı̆ıdır.

Periodontal hastalıklar sonucu tat ve lezzet duyularındaki kayıp kimsenin istemeyeceği bir durumdur. Her ne kadar araştırmamızda periodontal hastalıkların tedavisi ile tat duyuları arasında olumlu bir ilişki bulmuş olsak da bu ilişkinin mekanizması bilinmemektedir. Bildiğimiz kadarıyla periodontal hastalıklar ile tat duyusu arasındaki ilişkiyi ve mekanizmayı incelemiş bir çalışma literatürde henüz yer almamıştır, bu sebeple sonuçlarımızı bu ortamda yeteri kadar tartışma imkanı bulamadık. Bununla birlikte gingivitis ve periodontitisli hastalarda tedavi öncesi ve sonrası tat algılamadaki farklılıkları hazırladığımız 9 farklı konsantrasyondaki sıvı ile değerlendirdiğimiz bu çalışma bu konuda yapılacak daha sonraki çalışmalara rehber niteliğindedir. Doğadaki bütün canlıların kendi iç metabolizmasını düzenlemek, büyüyüp gelişmek ve canlılıklarını sürdürebilmek için kendi doğal metabolizmasına uygun maddeleri seçerek beslenmesi gerekmektedir. Besin maddelerinin seçimini sağlayan ölçü ve kontrol ise tat duyusu yardımıyla olmaktadır. ${ }^{24}$ Tat duyusu üzerinde etkinliği bulunan periodontal hastalıklar ile tat duyusu bozukluğu arasındaki ilișkiyi ve bu ilişkinin mekanizmasını açıklayacak daha geniş popülasyonlarda ve daha kapsamlı çalışmalara ihtiyaç vardır.

\section{SONUÇ}

Bu çalışmanın sonuçları periodontal hastalığa sahip bireylerde görülen tat duyusu bozukluğunun periodontal tedavi ile azaltılabileceğini göstermiştir.

\section{KAYNAKLAR}

1. Hummel T, Landis BN, Hüttenbrink KB. Smellandtastedisorders. GMS Curr Top Otorhinolaryngol Head Neck Surg 2011; 10: 1-15.

2. Oakley B, Benjamin RM. Neuralmechanism of taste. PhysiolRev 1966; 46: 173-211.

3. Hummel T, Landis BN, Huttenbrink KB. Dysfunction of thechemicalsensessmellandtaste. Laryngorhinootologie 2011; 90: 44-55.

4. Beers MH, Berkow R. TheMerck Manual of Geriatrics (3rd ed). Merck\&Colnc., USA; 2000.

5. Fark T, Hummel C, Hähner A, Nin T, Hummel T. Cha- racteristics of tastedisorders. Eur Arch Otorhinolaryngol 2013; 270: 1855-1860.

6. Abdollahi M, Radfar M. A Rewiev of drug-induced oral reactions. The Journal of Contemporary Dental Practice 2003; 13: 1-19.

7. Gokalp S, Dogan BG, Tekcicek M., Berberoglu A., Unluer $\mathrm{S}$. The oral health profile of adults and elderly, Turkey-2004. Clin Dent Res 2007; 31: 118.

8. Silness $\mathrm{J}$, Loe $\mathrm{H}$. Periodontaldisease in pregnancy II-correlation between oral hygiene and periodontal condition. Acta Odontol Scand 1964; 22: 121-135.

9. Loe $\mathrm{H}$, Silness J. Periodontal disease in pregnancy I-pravalence and severity. Acta Odontol Scand 1963; 21: 533-551.

10. Ainamo J, Bay I. Problems and proposals for recording gingivitis and plaque. Int Dent J 1975; 25: 229-235.

11. Armitage GC. Development of a classification system for periodontal diseases and conditions. Ann Periodontol 1999; 4: 1-6.

12. Delibasi C, Cehiz T, Akal UK, Yilmaz T. Evaluation of gustatory function in postmenopausal women. British Dent J 2003; 194: 447-449.

13. Linden GJ, Lyons A, Scannapieco FA. Periodontal systemic associations: review of the evidence. J Clin Periodontol 2013; 40: 8-19.

14. Scannapieco FA. Systemic effects of periodontal diseases. Dent Clin North Am 2005; 49: 533-550.

15. Ay ZY, Caglar F. The investigation of the relationship between obesity and periodontal status with anthropometric and bioelectric impedance methods. J Dent Fac Atatürk Uni 2010; 3: 139-144.

16. Borges TF, Regalo SC, Taba M Jr, Siessere S, Mestriner W Jr, Semprini M. Changes in masticatory performance and quality of life in individuals with chronic periodontitis. J Periodontol 2013; 84: 325-231.

17. Bosy A, Kulkarni GA, Rosenberg M, Mcculloch CA. Relationship of oral malador to periodontitis; evidence of independence in discrete suppopulations. J Periodontol 1994; 65: 37-46.

18. Bhattacharyya $\mathrm{N}$, Kepnes LJ. Contemporary assessment of the prevalence of smell and taste problems in adults. Laryngoscope 2015; 125:1102-1106.

19. Winkler S, Garg AK, Mekayarajjananoth $T$, Bakaeen LG, Khan E. Depressed taste and smell in geriatric patients. JADA 1999; 130: 1759-1765.

20. Hyde RJ, Feller RP, Sharon IM. Tongue brushing, dentifrice and age effects on taste and smell. J Dent Researc 1981; 60: 1730-1734.

21. Langan MJ, Yearick ES. Theeffects of improved oral hygiene on taste perception and nutrition of elderly. J Geront 1976; 31: 413-418.

22. Stevens DA. Individual diferences in taste perception. Food chemistry 1996; 56: 303-311. 
23. Karakus SŞ. Factor affecting perception of taste. J Tourism and Gastronomy Studies 2013; 1: 26-34.

24. Ceyhan O. Tat duyusu. A.Ü. Diş Hek. Fak. Der. 1977; 4: 97-112. 